\title{
Gonadectomy in mice of the inbred strain CE/J induces proliferation of sub-capsular adrenal cells expressing gonadal marker genes
}

\author{
Inga K Johnsen, Marc Slawik ${ }^{1}$, Igor Shapiro, Michaela F Hartmann², Stefan A Wudy², \\ Brendan D Looyenga ${ }^{3}$, Gary D Hammer ${ }^{3}$, Martin Reincke ${ }^{4}$ and Felix Beuschlein \\ Division of Endocrinology and Metabolism, Department of Internal Medicine II, Klinikum der Albert-Ludwigs-Universität, D-79106 Freiburg, Germany \\ ${ }^{1}$ Department of Clinical Biochemistry, University of Cambridge, Addenbrooke's Hospital, Cambridge, UK \\ ${ }^{2}$ Steroid Research Unit, Center of Child and Adolescent Medicine, Justus-Liebig-University Giessen, Germany \\ ${ }^{3}$ Division of Endocrinology and Metabolism, Department of Internal Medicine, University of Michigan, Ann Arbor, Michigan, USA \\ ${ }^{4}$ Medizinische Klinik - Innenstadt, Ludwig-Maximilians-University, Munich, Germany \\ (Requests for offprints should be addressed to F Beuschlein; Email: beuschlein@medizin.ukl.uni-freiburg.de)
}

\begin{abstract}
Mouse models of adrenal tumorigenesis have the potential to give insights in the dysregulation of adrenal growth and differentiation. The inbred mouse strain $\mathrm{CE} / \mathrm{J}$ has been reported to develop adrenal tumors upon gonadectomy (GDX) similar to mice with targeted deletions of the inhibin alpha subunit $\left(\operatorname{Inh}^{-/-}\right)$. We performed a detailed morphological and molecular characterization of adrenal glands from $\mathrm{CE} / \mathrm{J}$ mice $8-50$ weeks of age to define the cellular origin of these tumors as well as the spatial and temporal expression of marker genes associated with tumor growth. In contrast to the induction of $\mathrm{x}$-zone growth upon GDX in $\mathrm{Inh}^{-/-}$mice, GDX in CE/J mice induced the appearance of sub-capsular nests of densely packed cells that progress into adrenal tumors. Staining for proliferative cell nuclear antigen confirms a substantial increased in cellular proliferation within this subcapsular compartment and lack of apoptosis upon GDX. Induction of adrenal tumor growth was accompanied by
\end{abstract}

transcriptional changes that otherwise define gonadal endocrine cells. These regulated genes included transcription factors such as GATA-4, WT-1, FOG-1, and steroidogenic factor-1 (SF-1), peptide hormones such as Mullerianinhibiting substance (MIS), hormone receptors including luteinizing hormone and MIS receptor, and steroidogenic enzymes such as $\mathrm{P} 450 \mathrm{c} 17$ and $\mathrm{P} 450$ aromatase. The functional significance of steroid enzyme expression was demonstrated by a gradual increase of adrenal androgens after GDX. Taken together these data suggest that adrenal tumors in gonadectomized CE/J mice are direct derivatives from cells of the proposed sub-capsular stem cell zone. The distinct expression pattern of this cell population is consistent with a defect in the differentiation of these cells into a cell population with functional properties that otherwise define a gonadal endocrine phenotype.

Journal of Endocrinology (2006) 190, 47-57

\section{Introduction}

Adrenal masses are one of the most common endocrine tumors diagnosed. Although most adrenal tumors are endocrine-inactive adenomas, a considerable proportion are associated with hormonal hyperfunction (Barzon et al. 2002) or malignancy (Mantero et al. 2000). Over the last decade, several molecular pathways involved in adrenal carcinogenesis have been identified, and mouse models of adrenal tumorigenesis have aided substantially in the understanding of basic mechanisms in the regulation of adrenocortical growth and differentiation. However, early steps in the pathogenesis of adrenal tumors have not been elucidated in detail.

Only recently, murine adrenal tumor models have provided evidence that luteinizing hormone (LH) and the transforming growth factor- $\beta$ (TGF- $\beta$ ) ligand family members inhibin and activin play opposite roles in adrenocortical hormone secretion and cellular proliferation (Rilianawati et al. 1998, Kero et al. 2000, Beuschlein et al. 2003). Transgenic overexpression of LH induces adrenal steroidogenesis (Kero et al. 2000) and high levels of gonadotropins are required for the induction of adrenal tumorigenesis in different mouse models (Matzuk et al. 1994, Rilianawati et al. 1998). One of these models, which has provided a significant amount of information on the mechanistic roles of inhibin and activin in the adrenal, is the inhibin null $\left(\operatorname{Inh}^{-/-}\right.$) mouse, which spontaneously develops activin-secreting gonadal tumors and adrenocortical carcinomas upon gonadectomy (GDX) (Matzuk et al. 1994). As we have demonstrated, the adrenal phenotype in $\mathrm{Inh}^{-/-}$mice is indicative of $\mathrm{x}$-zone growth dysregulation. Development of activin-secreting gonadal 
tumors in $\mathrm{Inh}^{-/-}$mice is accompanied by a decrease in adrenal weight and regression of the x-zone. Activin, which plays a critical role as a paracrine and autocrine factor regulating cellular growth and differentiation, has been demonstrated to induce apoptosis and suppress proliferation in the human (Spencer et al. 1992, 1999) and murine adrenal cortex (Beuschlein et al. 2003). The ultimate cause of this regression in the murine adrenal cortex is the distinct $\mathrm{x}$-zonal expression pattern of activin receptor subunits and the intracellular mediator Smad-2, which results in a particular responsiveness of the $\mathrm{x}$-zone to activin. As a result, high levels of activin induce apoptosis specifically in the adrenal $\mathrm{x}$-zone, thus preventing adrenal tumorigenesis in the presence of activin-secreting gonadal tumors. Conversely, the surgical removal of activin-secreting gonadal tumors in Inh $^{-1-}$ is followed by unopposed $\mathrm{x}$-zone growth and ultimately by the development of adrenal tumors (Beuschlein et al. 2003).

The CE/J strain of mice, which bases on the extreme dilution strain established and maintained since 1920, has been characterized on a morphological basis in the 1940s. Intriguingly, the $\mathrm{CE} / \mathrm{J}$ strain shares several phenotypical similarities with the Inh ${ }^{-/-}$mouse. Like Inh ${ }^{-/-}$mice, the $\mathrm{CE} / \mathrm{J}$ strain is characterized by the occurrence of adrenocortical carcinoma when GDX is performed early in life (Woolley \& Little 1945). In addition, morphological studies on accessory reproductive organs in gonadectomized $\mathrm{CE} / \mathrm{J}$ mice have provided indirect evidence for the secretion of sex steroids from the adrenal tumors (Woolley \& Little 1946a). Since adrenal tumors in gonadectomized $\mathrm{Inh}^{-/-}$mice secrete sex steroids (Beuschlein et al. 2003), the adrenal phenotype in $\mathrm{CE} / \mathrm{J}$ mice points towards a dysregulation of $\mathrm{x}$-zone growth after GDX as the basis of adrenal tumor growth. However, based on the early morphological studies (Woolley \& Little 1946b) and recent reports on similar phenotypes in other inbred mouse strains (Bielinska et al. 2003, 2005), it seems likely that the precursor of tumor cells in $\mathrm{CE} / \mathrm{J}$ mice are located in the sub-capsular zone of the adrenal cortex.

The adrenal cortex is a dynamic organ in which senescing cells are constantly replaced by newly differentiated daughter cells. According to the cell migration model, each zone of the adrenal cortex is derived from a common pool of progenitor cells located in the periphery of the cortex, which migrates centripetally and populates the inner cortical zones upon differentiation (Belloni et al. 1978, Spencer et al. 1999). The characteristic zonation of the adrenal cortex in cellular compartments with distinct functional properties is tightly controlled to ensure structural plasticity of the adrenal cortex and to maintain hormonal homeostasis. We hypothesized that dysregulation of adrenal stem cell proliferation and differentiation could be the basis of adrenal tumorigenesis in $\mathrm{CE} / \mathrm{J}$ mice and undertook a detailed morphological and functional characterization of the adrenal phenotype of these mice.

\section{Materials and Methods}

\section{Experimental animals}

All experiments involving animals were performed in accordance with institutionally approved and current animal care guidelines. Male $\mathrm{CE} / \mathrm{J}$ mice were obtained by breeding mice of the inbred $\mathrm{CE} / \mathrm{J}$ background (Jackson ImmunoResearch Laboratories, West Grove, PA, USA), while $\mathrm{Inh}^{-/-}$mice were generated by breeding of heterozygous animals $\left(\mathrm{Inh}^{+/-}\right)$on an extensively outbred strain. Genotyping was performed as described earlier (Matzuk et al. 1994). All animals were maintained under standard conditions of temperature $\left(22^{\circ} \mathrm{C}\right)$ and lighting $(12 \mathrm{~h}$ light:12 h darkness) and ad libitum with food and water. To obtain a time-course of the testicular and adrenal phenotype of gonadectomized and non-gonadectomized $\mathrm{CE} / \mathrm{J}$ mice, a group of mice $(n=3-4)$ was euthanized at 8 , $14,20,26,38$, and 44 weeks of age, while another group of mice $(n=3-4)$ was gonadectomized at 2 weeks of age following the standard procedures and euthanized at the same time points. Accordingly, $\operatorname{Inh}^{-/-}$and wild-type controls were gonadectomized at 2-4 weeks of age and euthanized at 19-27 weeks. Non-gonadectomized controls of each genotype were euthanized at 9 weeks of age. Trunk blood for hormonal measurements was taken within $60 \mathrm{~s}$ after initial mouse handling and adrenals and testes were collected. Following microdissection, adrenal and testicular weights were measured and the tissues were snap frozen for protein/RNA extraction or immersed in para-formaldehyde (PFA) or Bouin's fixative for histological studies.

\section{Reverse transcription (RT)-PCR and real-time PCR}

Individual adrenals from 44-week-old gonadectomized and non-gonadectomized CE/J mice ( $n=2$ in each group) as well as the adrenals of the non-GDX and GDX Inh $^{-/-}$knockout and $\mathrm{Inh}^{+/+}$controls ( $n=2$ in each group) were used for RNA extraction using the Qiagen RNA mini kit (Qiagen) following the instructions of the manufacturer. cDNA was created from $1.0 \mu \mathrm{g}$ of total RNA using a reverse transcription kit (Promega). Aliquots of the cDNA samples were subjected to the subsequent PCR for semi- and to realtime PCR for quantitative measurements of mRNA levels. RT-PCR and real-time PCR amplifications were performed with the corresponding primer pairs, as given in Table 1.

The PCR was carried out using the Advantage 2 Polymerase Mix (BD Biosciences, Heidelberg, Germany) with 32-35 cycles of denaturation at $94^{\circ} \mathrm{C}$ for $20 \mathrm{~s}$, primer annealing and extension at $68^{\circ} \mathrm{C}$ for $20 \mathrm{~s}$. Amplification products were separated on a $1 \%$ agarose gel and stained with ethidium bromide.

Real-time PCR was performed using the FastStart DNA Master ${ }^{\text {Plus }}$ SYBR Green I reaction mix and the FastStart Taq DNA Polymerase (Roche) or the SYBR Premix Ex Taq (Cambrex, Baltimore, MD, USA) in an appropriate 
Table 1 Primer sequences used in reverse transcription- and real time-PCR experiments

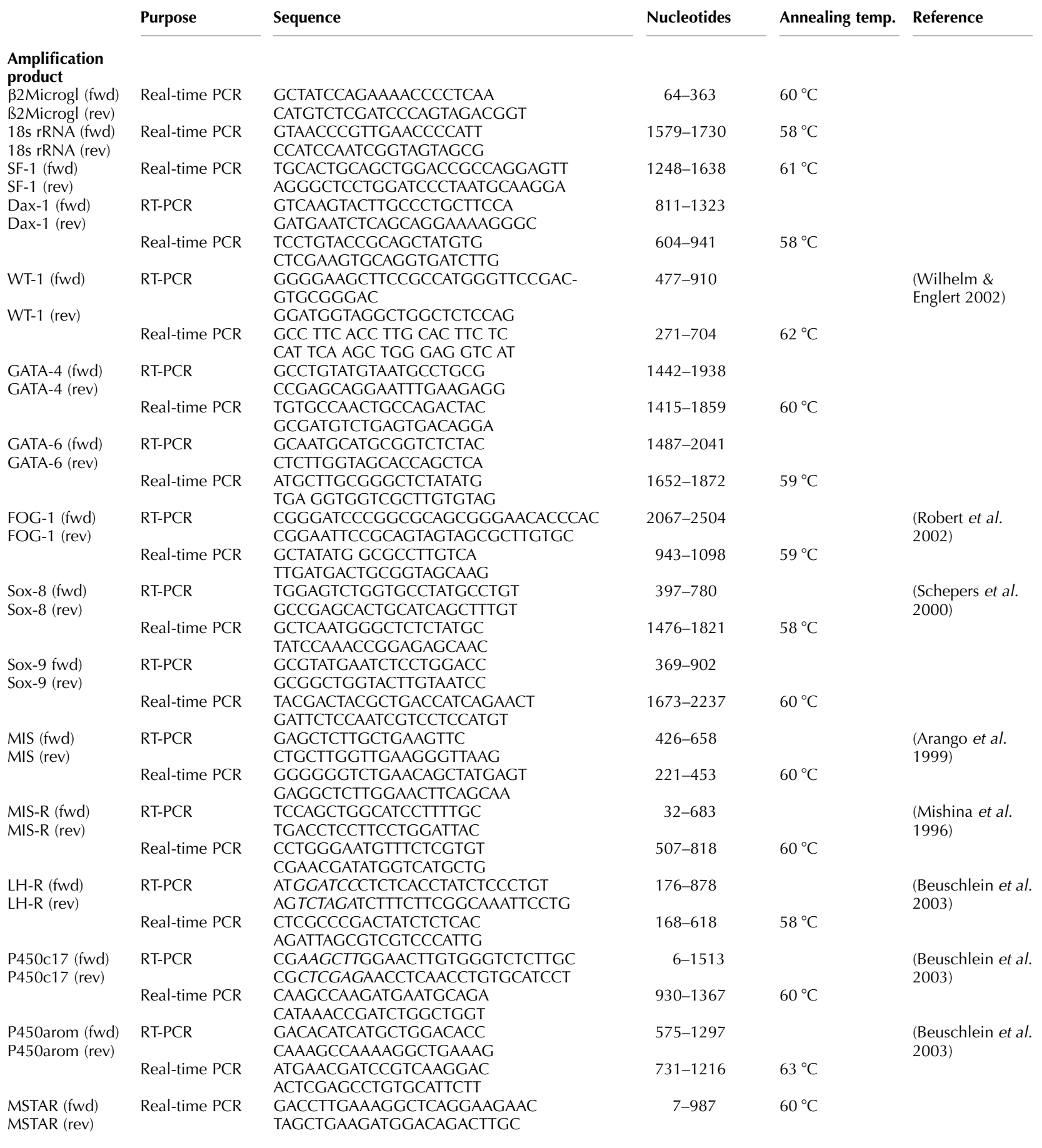

LightCycler. The real-time PCR conditions started with a preincubation at $95^{\circ} \mathrm{C}$ for $10 \mathrm{~min}$, followed by the amplification of $40-45$ cycles at $95^{\circ} \mathrm{C}$ for $10 \mathrm{~s}$, the annealing temperature (primer dependent as given in Table 1) for $6 \mathrm{~s}$ and the extension at $72{ }^{\circ} \mathrm{C}$, at which the time is calculated by the product in bp divided by 25 (Roche) or was run as a three-step PCR following the instructions of the manufacturer (Cambrex).

The melting curve analysis was performed between 65 and $95{ }^{\circ} \mathrm{C}\left(0 \cdot 1^{\circ} \mathrm{C} / \mathrm{s}\right)$ to determine the $T_{\mathrm{m}}$ of the amplified 
product and to exclude undesired primer dimers. Furthermore, the products were run on a $1 \%$ agarose gel to verify the amplified product.

Quantification was adjusted using the house-keeping gene $\beta 2$-microglobulin as well as $18 \mathrm{~s}$ rRNA. In both instances, comparable results were obtained. To facilitate overall comparison, expression levels of the particular genes were set as $100 \%$ for non-GDX control animals (non-GDX CE/J mice and non-GDX $\mathrm{Inh}^{+/+}$respectively), even though in some cases, the expression levels were not distinct from the value of the water-negative control.

\section{Histology, immunohistochemistry, and in situ hybridization}

Adrenal glands and testes were rapidly dissected and placed in $4 \%$ PFA for $3 \mathrm{~h}$ and Bouin's fixative overnight respectively. Tissues for histochemistry ( $n=3$ per group) were dehydrated, embedded in paraffin, sectioned, and stained with hematoxylin and eosin (H\&E) following the standard protocols. H\&E stained adrenal sections were examined with a standard light microscope using $50 \times$ magnification. Areas of the total cortex, the adrenal $\mathrm{x}$-zone, and tumor areas were quantified using the Spot software (Diagnostic Instruments, Sterling Heights, MI, USA) as described elsewhere (Beuschlein et al. 2003). In brief, to ensure a reliable comparison between the specimens, three adjacent sections from the middle portion of each individual adrenal were examined. In order to control for the spherical shape of the mouse adrenal gland, the $\mathrm{x}$-zonal area and tumor area were normalized for the total cortical area and were expressed as the $\mathrm{x}$-zone/total cortical area ratio and tumor/total area ratio, respectively.

For proliferative cell nuclear antigen (PCNA) and CYP17 immunohistochemistry, paraffin-embedded sections were rehydrated, blocked with $0 \cdot 3 \% \mathrm{H}_{2} \mathrm{O}_{2}$ in methanol for $10 \mathrm{~min}$, and incubated with blocking buffer for $15 \mathrm{~min}$. PCNA was immunolocalized overnight at $4{ }^{\circ} \mathrm{C}$ by means of a rabbit polyclonal antibody (Santa Cruz Biotechnology, Santa Cruz, CA, USA) in a dilution of 1:100 in blocking buffer containing 3\% BSA (Roche), 5\% goat serum (Jackson ImmunoResearch Laboratories), and $0.5 \%$ Tween 20, whereas CYP17 (courtesy of Dr Anita Payne, Stanford University, Palo Alto, CA, USA) was diluted 1:200 in blocking buffer. After rinsing for $15 \mathrm{~min}$ in PBS, secondary antibody (goat antirabbit biotinylated IgG (Vector Laboratories, Burlingame, CA, USA)) was applied for $30 \mathrm{~min}$ at room temperature. For the visualization of the bound CYP17 antibody, Vectastain Elite ABC system (Vector Laboratories) and Sigma Fast diaminobenzidine (Sigma) were used. Bound PCNA antibody was detected using the Santa Cruz Immunocruz Kit (Santa Cruz Biotechnology) according to the manufacturer's protocol. Presence of apoptotic cells was assayed using a terminal deoxynucleotidyl transferasemediated dUTP nick end labeling (TUNEL) detection kit (Promega) as recommended by the manufacturer.

PCNA and TUNEL stained adrenal sections from both groups were examined with a standard light microscope using
$400 \times$ magnification. Stained cell nuclei within the zona glomerulosa and outer zona fasciculata of three independent sections from two different animals per group were counted under standardized conditions. Cell counts are expressed as cell number/high power fields (HPF).

To analyze the mRNA expression of CYP17 and LH-receptor (LH-R), the paraffin-embedded sections were subjected to in situ hybridization as described previously (Beuschlein et al. 2004).

\section{Plasma hormone measurements}

Plasma steroid levels (dehydroepiandrosterone (DHEA), and testosterone) were measured using stable isotope dilution/gas chromatography-mass spectrometry as described earlier (Wudy et al. 2002).

\section{Statistical analysis}

All results are expressed as mean \pm s.E.M. Statistical comparisons were analyzed by ANOVA and Fisher's protective least significant difference test. Statistical significance is defined as $P<0 \cdot 05$ and is indicated as a star $\left(^{\star}\right)$ in the figures.

\section{Results}

Male CE/J mice do not develop testicular tumors and do not suffer from wasting syndrome

As mice of the inbred CE/J strain have been reported to develop adrenal tumors upon GDX (Woolley \& Little 1946b), they share phenotypical similarities with Inh ${ }^{-1-}$ mice. Another characteristic of Inh ${ }^{-/-}$is the spontaneous development of activinsecreting gonadal tumors that result in the early death of the animals due to a wasting-like syndrome (Zajicek et al. 1986, Matzuk et al. 1994). However, unlike $\mathrm{Inh}^{-1-}$ mice, testicular weight in $\mathrm{CE} / \mathrm{J}$ mice did not change substantially during lifetime (8 weeks, $112 \cdot 7 \pm 5 \cdot 0 \mathrm{mg} ; 14$ weeks, $108 \cdot 3 \pm 0.7 \mathrm{mg} ; 20$ weeks, $111 \cdot 5 \pm 5 \cdot 2 \mathrm{mg} ; 26$ weeks, $126 \cdot 0 \pm 11 \cdot 0 \mathrm{mg} ; 38$ weeks, $127 \cdot 3 \pm 7 \cdot 6 \mathrm{mg} ; 44$ weeks, $125 \cdot 3 \pm 3 \cdot 8 \mathrm{mg}$; Fig. 1 , lower panel) and no histological evidence of testicular tumor growth was detectable in any of the animals (Fig. 1, upper panel). $\mathrm{CE} / \mathrm{J}$ animals did not suffer from wasting syndrome and premature death (body weight: 8 weeks, $19 \cdot 3 \pm 0 \cdot 5 \mathrm{~g} ; 14$ weeks, $22 \cdot 7 \pm 0 \cdot 5 \mathrm{~g} ; 20$ weeks, $25 \cdot 0 \pm 1 \cdot 0 \mathrm{~g} ; 26$ weeks, $30 \cdot 0 \pm 0 \cdot 9 \mathrm{~g} ; 38$ weeks, $25 \cdot 6 \pm 0 \cdot 7 \mathrm{~g} ; 44$ weeks, $28 \cdot 3 \pm$ $2 \cdot 5$ g; Fig. 1, lower panel) consistent with the lack of elevated gonadal activin.

\section{Gonadectomy in CE/J mice results in development of sub-capsular tumor nests and delayed regression of the $\mathrm{x}$-zone}

Histological examination of adrenals from non-gonadectomized (w/o GDX) male CE/J mice proved the expected x-zone regression after the onset of puberty with a loss of the $\mathrm{x}$-zone 

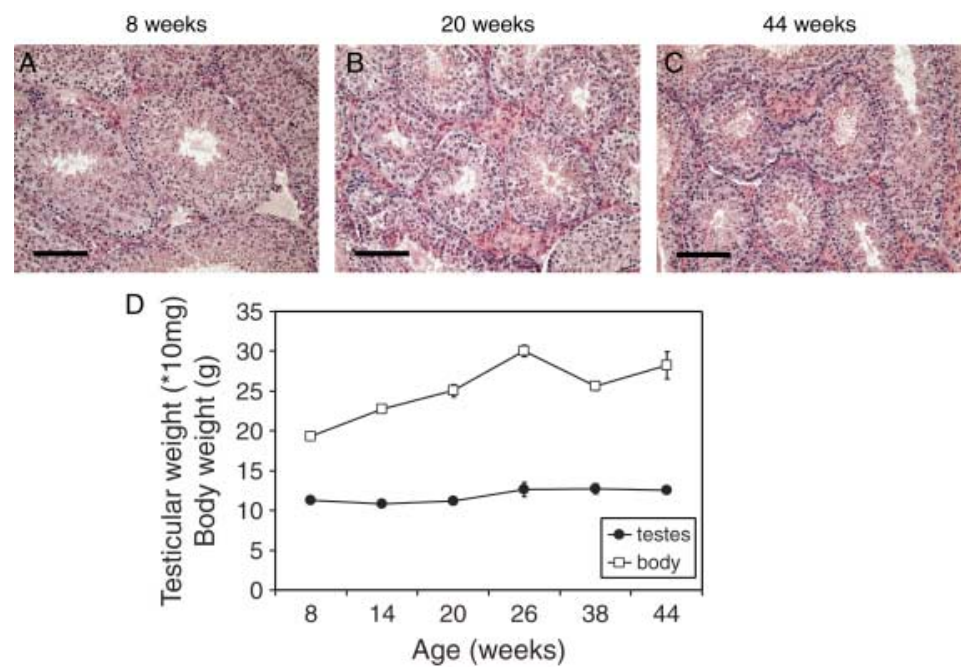

\begin{abstract}
Figure 1 Male mice of the inbred strain CE/J do not develop testicular tumors and do not die from wasting syndrome. (A-C) Hematoxylin and eosin stained testicular sections from 8- to 44-week-old animals demonstrating regular morphology without evidence of tumor growth. (D) Time-course for body weight and testicular weight from male CE/J mice $(n=3-4)$ without indication of (tumor-induced) increase of testicular weight. Bars in $(A-C)=20 \mu \mathrm{m}$.
\end{abstract}

after 8 weeks of age (x-zone area/cortical area: 8 weeks, $21 \cdot 6 \pm$ $3 \cdot 7 \% ; 14-44$ weeks, $0 \cdot 0 \pm 0 \cdot 0 \%$; Fig. $2 \mathrm{~A}-\mathrm{E}, \mathrm{L})$. In contrast, GDX was accompanied by a significantly larger $\mathrm{x}$-zone area, compared to non-gonadectomized animals of the same age, that decreased gradually over a longer period of time $(8$ weeks, $29 \cdot 3 \pm 0 \cdot 9 \%, P=0 \cdot 011 ; 14$ weeks, $32 \cdot 4 \pm 3 \cdot 7 \%, P<0 \cdot 0001$; 20 weeks, $27 \cdot 4 \pm 1 \cdot 0 \%, P<0 \cdot 0001 ; 26$ weeks, $16 \cdot 9 \pm 1 \cdot 6 \%$, $P<0 \cdot 0001 ; 38$ weeks, 9.1 $\pm 1 \cdot 3 \%, P=0 \cdot 031 ; 44$ weeks, $6 \cdot 7 \pm 1 \cdot 4 \%, P=0 \cdot 067$; Fig. $2 \mathrm{~F}-\mathrm{J}, \mathrm{L})$. In addition, $\mathrm{x}$-zone regression in gonadectomized animals was accompanied by the appearance of densely packed cell nests in the sub-capsular adrenal cortex that increased in size over time and eventually developed into a tumor (tumor area/cortical area: 20 weeks, $4 \cdot 6 \pm 0 \cdot 6 \% ; 26$ weeks, $7 \cdot 0 \pm 0 \cdot 4 \% ; 38$ weeks, $19 \cdot 6 \pm 0 \cdot 4 \% ; 44$ weeks, $31 \cdot 5 \pm 2 \cdot 1 \%$; Fig. $2 \mathrm{H}-\mathrm{J})$. These results demonstrate that GDX-induced adrenocortical tumors in CE/J mice are situated within the sub-capsular zone, unlike adrenal tumors in $\mathrm{Inh}^{-/-}$ mice, which are situated within or contiguous to the $\mathrm{x}$-zone. Overall, GDX resulted in a small, albeit significant higher adrenal weight at each time point ( 8 weeks, $5 \cdot 8 \pm 0 \cdot 4 \mathrm{mg}, P=$ $0 \cdot 02 ; 14$ weeks, $6 \cdot 6 \pm 0 \cdot 3 \mathrm{mg}, P=0 \cdot 0008 ; 20$ weeks, $6 \cdot 4 \pm$ $0.0 \mathrm{mg}, P=0.009 ; 26$ weeks, $6.7 \pm 0.7 \mathrm{mg}, P=0.003 ; 38$ weeks, $8.5 \pm 0.6 \mathrm{mg}, P<0.0001 ; 44$ weeks, $8.8 \pm 0.5 \mathrm{mg}$, $P<0 \cdot 0001)$ as compared to non-gonadectomized animals ( 8 weeks, $4 \cdot 4 \pm 0.5 \mathrm{mg} ; 14$ weeks, $4 \cdot 6 \pm 0.4 \mathrm{mg}$; 20 weeks, $4 \cdot 8 \pm 0 \cdot 2 \mathrm{mg} ; 26$ weeks, $4 \cdot .2 \pm 0 \cdot 2 \mathrm{mg} ; 38$ weeks, $4 \cdot 7 \pm$ $0 \cdot 1 \mathrm{mg} ; 44$ weeks, $4 \cdot 8 \pm 0 \cdot 2 \mathrm{mg} ;$ Fig. $2 \mathrm{~K})$. Moreover, tumor development in gonadectomized mice was accompanied by a significant increase in adrenal weight in comparison to earlier time points (adrenal weight 8 weeks, $5 \cdot 8 \pm 0 \cdot 4 \mathrm{mg}$ vs 38 weeks,
$8 \cdot 5 \pm 0 \cdot 6 \mathrm{mg}, P=0 \cdot 0003$ and 44 weeks, $8 \cdot 8 \pm 0 \cdot 5 \mathrm{mg}, P<$ $0 \cdot 0001$ respectively).

Gonadectomy in CE/J mice is followed by an increase in sub-capsular adrenocortical proliferation and lack of adrenocortical apoptosis

To further define the underlying growth dysregulation in the adrenal cortices of gonadectomized $\mathrm{CE} / \mathrm{J}$ mice and in an attempt to delineate the cellular origin of the developing adrenal tumors, we determined the number and distribution of proliferating and apoptotic cells in adrenals from nongonadectomized (w/o GDX) and gonadectomized (GDX) $\mathrm{CE} / \mathrm{J}$ mice. In accordance with the observed tumor development in the sub-capsular zone, PCNA-positive cells were mainly restricted to the sub-capsular cells (Fig. 3C and D) with a significant higher number of proliferating cells $(20$ weeks, $200 \cdot 3 \pm 16 \cdot 6$; 38 weeks, $810 \cdot 0 \pm 72 \cdot 7)$ in comparison to non-gonadectomized animals (20 weeks, $41 \cdot 7 \pm 4 \cdot 6$, $P=0 \cdot 0008 ; 38$ weeks, $56 \cdot 0 \pm 11 \cdot 2, P<0 \cdot 0001$; Fig. $3 \mathrm{~A}$ and $B)$. In contrast, the number of apoptotic cells per high power field was not different after GDX (20 weeks, $10 \cdot 0 \pm 1 \cdot 5 ; 38$ weeks, $8 \cdot 7 \pm 7 \cdot 2$; Fig. $3 \mathrm{G}$ and $\mathrm{H}$ ) as compared to nongonadectomized animals at these time points (20 weeks, $7 \cdot 7 \pm 2 \cdot 7, P=0 \cdot 74 ; 38$ weeks, $3 \cdot 3 \pm 0 \cdot 7, P=0 \cdot 47$; Fig. $3 \mathrm{E}$ and F). Intriguingly, the tumor cell population which is characterized by high proliferation showed virtually no apoptotic cells (Fig. 3H, insert). Taken together, these results indicate that GDX is followed by high proliferation of the sub-capsular cell population, which results in the unopposed growth of tumor cells. 

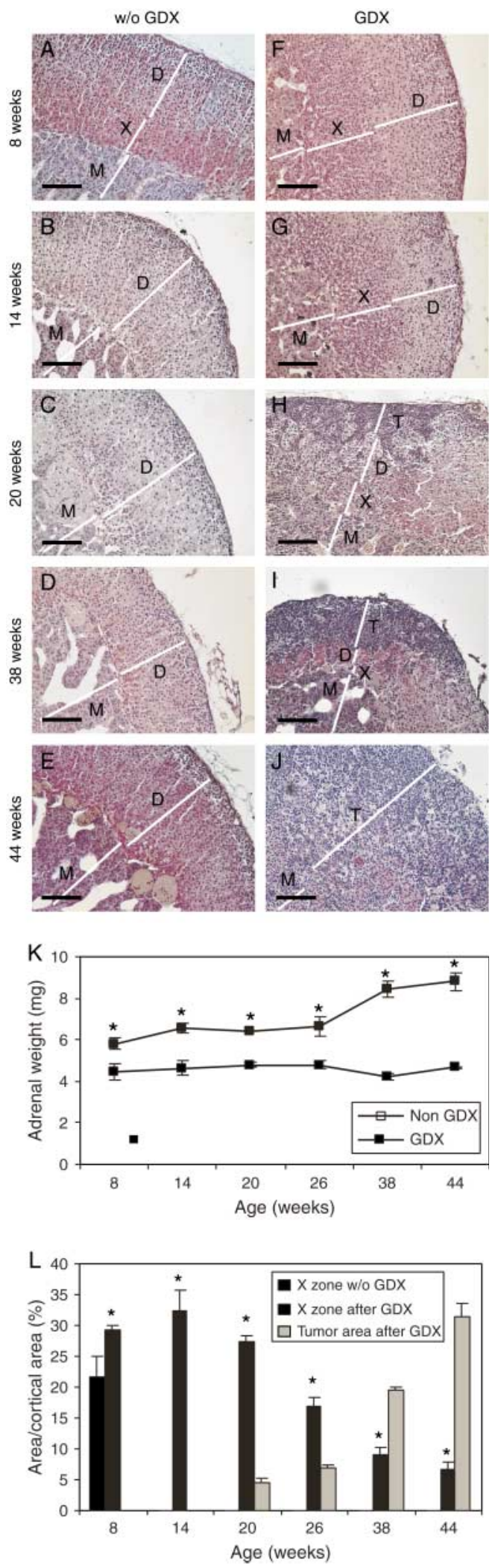

Adrenal tumors in gonadectomized $\mathrm{CE} / \mathrm{J}$ and $\mathrm{Inh}^{-1-}$ mice express gonadal marker genes and secrete sex steroids

To further define the functional properties of adrenal tumors in gonadectomized $\mathrm{CE} / \mathrm{J}$ mice, we determined the expression pattern of a variety of marker genes. Interestingly, adrenal tumors in $\mathrm{CE} / \mathrm{J}$ mice express a distinct pattern of steroidogenic enzymes, including $17 \alpha$-hydroxylase (P450c17; non-GDX $100 \cdot 0 \pm 7 \cdot 1 \%$ vs GDX $3756 \cdot 3 \pm$ $75 \cdot 4 \%, P<0 \cdot 0001)$ and aromatase (P450c19; non-GDX $100 \cdot 0 \pm 31 \cdot 7 \%$ vs GDX $1800 \cdot 0 \pm 200 \cdot 0 \%, P=0 \cdot 001)$, peptide hormone such as Mullerian-inhibiting substances (MISs; $P=0 \cdot 0012$ ), and hormone receptors including LH-R $(P=0 \cdot 0008)$ and MIS receptor $(P<0 \cdot 0001)$ that otherwise define gonadal endocrine function. In addition, transcription factors such as GATA-4 $(P=0 \cdot 0005)$, Wilms tumor gene-1 (WT-1; $P<0 \cdot 0001)$, and steriodogenic factor-1 (SF-1; $P=0 \cdot 0029)$ were significantly up-regulated after GDX, while other transcription factors such as FOG-1 $(P<0 \cdot 0001)$ and GATA-6 $(P=0 \cdot 0004)$ were downregulated. In contrast, Sox- 8 and DAX-1 did not significantly different between the groups (Fig. 4A and B).

As demonstrated in Fig. 4C, a similar expression profile was present in adrenal tumors from gonadectomized $\mathrm{Inh}^{-1-}$ animals with significant increase of GATA-4, MIS receptor, CYP17, and CYP19. In contrast, no significant changes in the expression pattern of these genes were evident in gonadectomized wild-type controls, indicating that in addition to GDX, transcriptional activation of these genes is dependent on adrenal tumorigenesis.

To localize some of the up-regulated genes, in situ hybridization and immunohistochemistry were performed, which demonstrated expression of P450c17 and LH-R expression restricted to the tumor cells (Fig. 5C and I) and lack of expression in adjacent areas of morphologically normal adrenal cortex (Fig. 5B and $\mathrm{H}$ ). To investigate the functional significance of the expression pattern of steroidogenic enzymes, hormonal profiles of gonadectomized CE/J mice were determined. The detected increase of the adrenal androgen DHEA (Fig. 5J) as well as testosterone (Fig. 5K) during the time-course experiment in gonadectomized CE/J mice is in line with the presence of functional active $17 \alpha-$ hydroxylase/17,20 lyase activity in adrenal tumors.

Figure 2 Time-course for adrenal morphology, weight, and zonal distribution in non-gonadectomized (w/o GDX; A-E) and gonadectomized (GDX; F-J) CE/J mice at 8 weeks (A, F), 14 weeks (B, G), 20 weeks $(C, H), 38$ weeks $(D, I)$, and 44 weeks $(E, J)$ of age.

Whereas the $x$-zone regresses in non-gonadectomized mice within the first 14 weeks of age $(A, B, L)$, it is retained in gonadectomized animals for a longer period of time before it gradually regresses ( $\mathrm{F}-\mathrm{I}$, L). In gonadectomized mice, dense, sub-capsular tumor nests appear $(\mathrm{H})$, which eventually develop into adrenocortical tumors $(\mathrm{I}, \mathrm{J})$. Bars in $(\mathrm{A}-\mathrm{J})=100 \mu \mathrm{m}$. D, definitive zone; $\mathrm{X}, \mathrm{X}$-zone; $\mathrm{M}$, medulla; $T$, tumor. Stars in $(\mathrm{L})$ denote significant differences in $\mathrm{X}$ zone area between gonadectomized and non-gonadectomized animals from the same age group. 


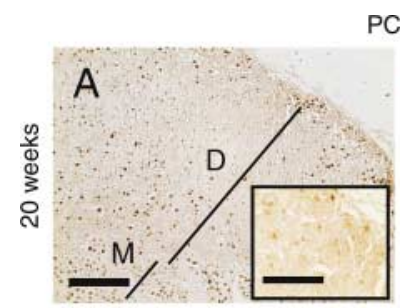

PCNA

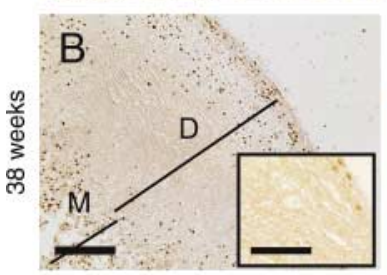

w/o GDX
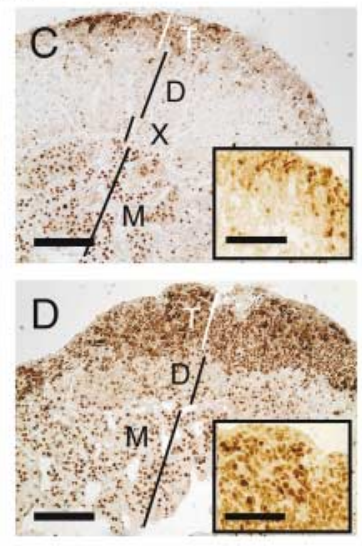

GDX
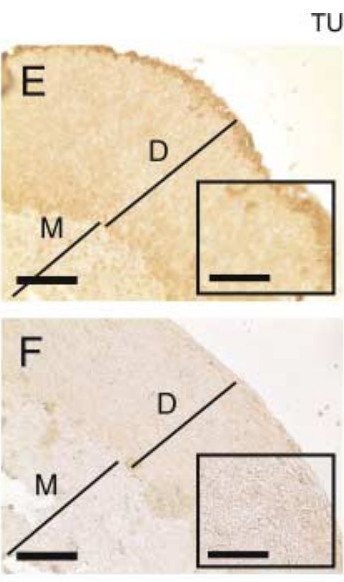

w/o GDX
TUNEL
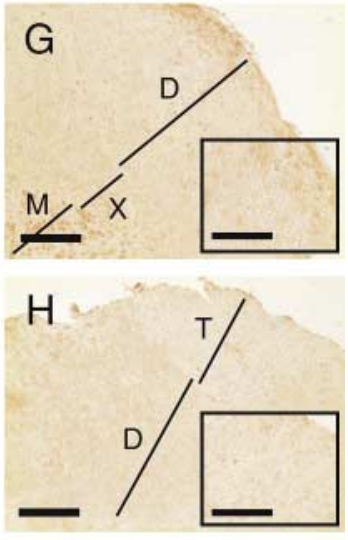

GDX

Figure 3 Distribution of proliferating (PCNA immunohistochemistry; A-D) and apoptotic (TUNEL staining; E-H) cells in adrenals from non-gonadectomized $(A, B, E, F)$ and gonadectomized $(C, D, G, H) C E / J$ mice at different time points. Gonadectomy is followed by an increase in the number of PCNA, mainly found in the sub-capsular tumor cell nests (C, D). In contrast, while the number of TUNEL-positive cells after GDX $(G, H)$ is comparable with non-gonadectomized mice (E, F), the tumor cell population, which is characterized by high proliferation, shows no apoptotic cells (magnified tumor area in $\mathrm{H}$ insert). Bars in $(\mathrm{A}-\mathrm{H})=100 \mu \mathrm{m}$; for high magnification inserts $=50 \mu \mathrm{m} ; \mathrm{D}$, definitive zone; $\mathrm{X}, \mathrm{x}$-zone; $\mathrm{M}$, medulla; $\mathrm{T}$, tumor.

Taken together, these data demonstrate the expression of distinct transcription factors, receptors, and steroidogenic enzymes otherwise expressed in gonadal endocrine cells suggesting a differentiation defect as part of the adrenal phenotype in gonadectomized $\mathrm{CE} / \mathrm{J}$ mice.

\section{Discussion}

The overall similar adrenal phenotype of $\operatorname{Inh}^{-/-}$mice and $\mathrm{CE} / \mathrm{J}$ mice-induction of adrenal tumorigenesis by GDXprompted us to compare morphological and molecular alterations initiated by surgical GDX in adrenal glands in these two animal models. As we demonstrate, GDX in CE/J mice is accompanied by development of sub-capsular tumor nests that are characterized by a high proliferation index as measured by PCNA staining. These findings provide evidence that in contrast to $\mathrm{Inh}^{-/-}$mice, which are characterized by tumor growth within or contiguous to the adrenal x-zone (Beuschlein et al. 2003), adrenal tumors in $\mathrm{CE} / \mathrm{J}$ mice derive from the sub-capsular zone of the adrenal cortex similar to other susceptible strains of mice (Bielinska et al. 2003, 2005). The shared gonadal-like phenotype of the adrenal tumors in both strains, and the clear involvement of the $\mathrm{x}$-zone in Inh $^{-1-}$ mice indicate that both tumors arise from defects in the differentiation and maturation of $x$-zone cells. However, the results from our present study suggest that adrenal tumorigenesis in $\mathrm{CE} / \mathrm{J}$ mice reflects dysregulation at an earlier stage that also includes a migration defect of cells descent to be x-zone cells. Indeed, an increasing body of evidence indicates that a common pool of stem cells that reside in this sub-capsular cellular compartment is likely to play a key role for adrenal physiology as distributors of all adrenocortical cells that migrate centripetally upon differentiation (Zajicek et al. 1986, Kataoka et al. 1996). Thus, adrenal tumorigenesis in CE/J mice might be of particular interest as a model of adrenal stem cell dysregulation.

The physiologic role of the murine adrenal x-zone, which becomes evident histologically at 10-14 days of age and subsequently begins to degenerate in males, coinciding with sexual maturity (Howard-Miller 1928), is not defined. In accordance with earlier findings demonstrating prevention of $\mathrm{x}$-zone degeneration in male mice by castration (HowardMiller 1928, Beuschlein et al. 2003), GDX delays x-zone degeneration and induces adrenal tumor formation in both strains of mice. In addition, at later time points, when adrenal tumors develop, the x-zone cross-sectional area gradually decreases, indicating that the development of adrenal tumors might directly or indirectly affect x-zone growth. Indeed, in $\mathrm{Inh}^{-/-}$mice, the pathological regression of the $\mathrm{x}$-zone is induced by high levels of tumoral activin that result in selective apoptosis of $\mathrm{x}$-zone due to their unique expression of activin receptors and the downstream effector Smad-2 (Beuschlein et al. 2003). In contrast, adrenal tumors in $\mathrm{CE} / \mathrm{J}$ mice do not display elevated activin mRNA levels (data not shown), indicating that in this mouse, model high levels of activin are not required for the observed tumor-induced x-zone regression. In fact, the role of activin for physiological $\mathrm{x}$-zone regression during puberty in male mice and during first pregnancy in female animals remains unproven. Other potential candidates involved in this process include sex steroids and gonadotropins (Howard-Miller 1928). Since the murine adrenal cortex is deprived of a functional equivalent of the zona reticularis and lacks expression of $\mathrm{P} 450 \mathrm{c} 17$, the mouse 



C


$\square \mathrm{WT}$
$\square \mathrm{INH}^{-/-}$ 
adrenal does not secrete adrenal androgens. However, adrenal tumors in CE/J mice not only express steroid enzymes required for sex-steroid production, but also adrenal tumor development is accompanied by increasing levels of serum DHEA and testosterone. Thus, sex steroids secreted by the adrenal tumors or secondary suppression of gonadotropins could be responsible for $\mathrm{x}$-zone regression in these animals.

During development, numerous transcriptional cascades are utilized to ensure tight control over cellular proliferation and proper spatio-temporal expression of target genes. A gonadal specific target gene which is expressed in adrenal tumors of $\mathrm{CE} / \mathrm{J}$ mice is the Mullerian-inhibiting substance (MIS), a glycoprotein dimer that-like inhibin and activin-belongs to the TGF- $\beta$ super-family (Lee $\&$ Donahoe 1993). Secretion of MIS by fetal sertoli cells is essential for normal male sex differentiation, since it induces regression of the Mullerian ducts in the developing male embryo. The specific expression in sertoli and granulosa cells has provided even diagnostic usefulness of the MIS gene for sub-classification of gonadal tumors (Rey et al. 2000). The gonadal restricted expression of the MIS gene requires a specific combination of transcription factors, including the zinc finger factor GATA-4 and the nuclear receptor SF-1, as well as Sox-9 and WT-1 (De Santa Barbara et al. 1998, Nachtigal et al. 1998, Viger et al. 1998).

WT-1 is a zinc finger-containing transcription factor, which has been implicated in the development of the indifferent gonad prior to sexual differentiation as well as in the etiology of certain neoplasia. Interestingly, GATA-4 together with WT-1 is up-regulated in adrenal tumors from gonadectomized CE/J mice. Thus, adrenal tumors in gonadectomized $\mathrm{CE} / \mathrm{J}$ mice resemble the expression pattern of transcription factors required for the expression of MIS in sertoli cells. In vivo and in vitro data suggest a pathway in which the products of the WT-1 and Lhx-9 genes activate expression of SF-1 and thus mediate early gonadogenesis (Wilhelm \& Englert 2002). As SF-1 levels are slightly up-regulated in adrenals from gonadectomized $\mathrm{CE} / \mathrm{J}$ mice, these data are in line with the concept of transcriptional activation of the SF-1 promoter by WT-1 as part of the dedifferentiation in these adrenal tumors.

The friend of GATA proteins (FOG: FOG-1 and FOG-2) can act as either enhancers or repressors of GATA transcriptional activity, depending on the cell and promoter context. It has been reported that the FOG proteins are co-expressed with GATA factors in testicular cells in which they differentially repress the promoter activities of several GATA-dependent target genes (Robert et al. 2002).
Intriguingly, FOG-1 expression is down-regulated in adrenal tumors from gonadectomized CE/J mice, in line with the concept of loss of repression of GATA-dependent transcriptional activation of target genes such as LH-R, CYP17, and CYP19 (Bielinska et al. 2003, 2005).

Although CE/J mice carry a polymorphism in the gene encoding SF-1 (SF-1 ${ }^{\mathrm{S} 172}$, data not shown), which has been associated with lower steroidogenic capacity and possibly higher susceptibly of GDX-induced adrenal tumorigenesis (Bielinska et al. 2003), it remains unclear from the data presented herein, which steps are the initial dysregulated events that induce adrenal tumor formation in these animals. GDX induces both a decrease of gonadal hormones (including inhibin and sex steroids) and an increase of gonadotropins (including LH). Chronically elevated levels of LH have been demonstrated to induce adrenal LH-R expression (Kero et al. 2000, Beuschlein et al. 2003) and boost adrenal tumor growth (Beuschlein et al. 2003, Mikola et al. 2003), depending on the strain background or targeted genetic alterations. As we could demonstrate, activin, which is secreted from gonadal tumors in Inh ${ }^{-/-}$mice, leads to the induction of $x$-zone apoptosis, thus preventing the growth of $\mathrm{x}$-zone derived adrenal tumors (Beuschlein et al. 2003). Since $\mathrm{CE} / \mathrm{J}$ animals are not prone to spontaneous gonadal tumor growth, activin as a repressor of adrenal tumor growth is not likely to play a similar key role in the pathophysiology of CE/J mice. However, high levels of $\mathrm{LH}$ might be sufficient to cause the adrenal phenotype in CE/J mice, as seen after GDX, a hypothesis which will be tested by introducing transgenic $\mathrm{LH}$ overexpression on the $\mathrm{CE} / \mathrm{J}$ background.

In conclusion, the dysregulation of adrenal growth in gonadectomized CE/J, DBA/2J (Bielinska et al. 2003), nude mice (Bielinska et al. 2005), and $\mathrm{Inh}^{-1-}$ mice (Beuschlein et al. 2003) is accompanied by a differentiation defect that drives adrenocortical cell differentiation towards a gonadal phenotype. The LH dependency of adrenal tumorigenesis in these tumor models is reminiscent of the clinical situation in patients with chronically elevated levels of proopiomelanocortin peptides due to steroid hydroxylase deficiencies, who develop adrenal rest tumors in the gonads (Stikkelbroeck et al. 2001). It is tempting to speculate that the ability of the adrenal stem cell population to mimic gonadal endocrine function might reflect the common embryological origin of adrenocortical and gonadal cells from adjacent areas of the urogenital ridge during early development (Smith \& Mackay 1991). In fact, expression of $\mathrm{P} 450 \mathrm{c} 17$ has been demonstrated in a

Figure 4 (A) Semi-quantitative RT-PCR panel of adrenals from gonadectomized (GDX) and non-gonadectomized (w/o GDX) CE/J mice. (B) Expression levels by means of real-time PCR analysis for CE/J mice with non-gonadectomized mice set as $100 \%$. In accordance with the semi-quantitative RT-PCR analysis, a significant increase in the expression of transcription factors such as SF-1, WT-1, and GATA-4 is evident, whereas GATA-6 and FOG-1 expression is down-regulated in adrenals from gonadectomized animals. In addition, Mullerian-inhibiting substance (MIS) and MIS receptor (MIS-R) as well as LH-R and steroidogenic enzymes such as $17 \alpha$-hydroxylase (CYP17) and aromatase


controls (with non-gonadectomized wild-type animals set as $100 \%$ ) demonstrate similar expressional changes for GATA-4, MIS-R, CYP17, and CYP19 only in adrenal tumors from gonadectomized $\mathrm{Inh}^{-1-}$ animals, whereas gonadectomy in wild-type animals does not significantly affect transcriptional levels. Stars denote significant differences in expression levels between GDX and non-GDX animals, whereas a cross indicates significant differences between gonadectomized inhibin knockout mice (Inh ${ }^{-1-}$ ) and wild-type controls (WT). 



Figure 5 In situ hybridization (A-C) and immunohistochemistry (D-F) for $17 \alpha$-hydroxylase (CYP17) and in situ hybridization for LH-R (G-I) in adrenals from gonadectomized CE/J mice at 8, 38, and 50 weeks of age, demonstrating staining specifically in tumorous areas. High magnification of immunohistochemical staining (D-F) and control reactions for in situ hybridization with sense probes $(A-C, G-I)$ are shown as inserts. Bars including low magnification inserts $=100 \mu \mathrm{m}$; bars in high magnification inserts $(D-F)=20 \mu \mathrm{m} ; \mathrm{D}$, definitive zone; $X$, $x$-zone; $M$, medulla; $T$, tumor. Time-course of steroid profile in gonadectomized CE/J mice suggesting functional significance of up-regulated expression of CYP17 in adrenal tumors with increase of the adrenal androgen DHEA $(\mathrm{J})$ as well as testosterone (K).

specific spatio-temporal pattern in a distinct cell population of the developing mouse adrenal (Keeney et al. 1995), highlighting the concept of closely related progenitor cells in adrenal and gonadal development.

\section{Acknowledgements}

We are indebted to Dr Anita Payne (Stanford University School of Medicine, Stanford, CA) for the generous gift of the anti-CYP17 antibody as well as to the late Roy Hertz and George Chrousos, who drew our attention to the manuscript which originally described the adrenal phenotype of CE/J mice (Wolley \& Little 1946a).

\section{Funding}

This work was supported by a grant from the WilhelmSander-Stiftung to F B and M R (2003.145.1) and a grant from the Landesstiftung Baden-Württemberg (P-LS-ASN/5) 
to F B. The authors declare that there is no conflict of interest that would prejudice the impartiality of this scientific work.

\section{References}

Arango NA, Lovell-Badge R \& Behringer RR 1999 Targeted mutagenesis of the endogenous mouse Mis gene promoter: in vivo definition of genetic pathways of vertebrate sexual development. Cell 99 409-419.

Barzon L, Fallo F, Sonino N \& Boscaro M 2002 Development of overt Cushing's syndrome in patients with adrenal incidentaloma. European Journal of Endocrinology 146 61-66.

Belloni AS, Mazzocchi G, Meneghelli V \& Nussdorfer GG 1978 Cytogenesis in the rat adrenal cortex: evidence for an ACTH-induced centripetal cell migration from the zona glomerulosa. Archives Anatomia, Histologia, Embryologia 61 195-205.

Beuschlein F, Looyenga BD, Bleasdale SE, Mutch C, Bavers DL, Parlow AF, Nilson JH \& Hammer GD 2003 Activin induces x-zone apoptosis that inhibits luteinizing hormone-dependent adrenocortical tumor formation in inhibin-deficient mice. Molecular Cell Biology 23 3951-3964.

Beuschlein F, Looyenga BD, Reincke M \& Hammer GD 2004 Role of the inhibin/activin system and luteinizing hormone in adrenocortical tumorigenesis. Hormone and Metabolic Research 36 392-396.

Bielinska M, Parviainen H, Porter-Tinge SB, Kiiveri S, Genova E, Rahman N, Huhtaniemi IT, Muglia LJ, Heikinheimo M \& Wilson DB 2003 Mouse strain susceptibility to gonadectomy-induced adrenocortical tumor formation correlates with the expression of GATA-4 and luteinizing hormone receptor. Endocrinology 144 4123-4133.

Bielinska M, Genova E, Boime I, Parviainen H, Kiiveri S, Leppaluoto J, Rahman N, Heikinheimo M \& Wilson DB 2005 Gonadotropin-induced adrenocortical neoplasia in NU/J nude mice. Endocrinology 146 3975-3984.

De Santa Barbara P, Bonneaud N, Boizet B, Desclozeaux M, Moniot B, Sudbeck P, Scherer G, Poulat F \& Berta P 1998 Direct interaction of SRY-related protein SOX 9 and steroidogenic factor 1 regulates transcription of the human antiMullerian hormone gene. Molecular Cell Biology 18 6653-6665.

Howard-Miller E 1928 A transitory zone in the adrenal cortex which shows age and sex relationships. American Journal of Anatomy 40 251-293.

Kataoka Y, Ikehara Y \& Hattori T 1996 Cell proliferation and renewal of mouse adrenal cortex. Journal of Anatomy 188 375-381.

Keeney DS, Jenkins CM \& Waterman MR 1995 Developmentally regulated expression of adrenal 17 alpha-hydroxylase cytochrome $\mathrm{P} 450$ in the mouse embryo. Endocrinology 136 4872-4879.

Kero J, Poutanen M, Zhang FP, Rahman N, McNicol AM, Nilson JH, Keri RA \& Huhtaniemi IT 2000 Elevated luteinizing hormone induces expression of its receptor and promotes steroidogenesis in the adrenal cortex. Journal of Clinical Investigation 105 633-641.

Lee MM \& Donahoe PK 1993 Mullerian inhibiting substance: a gonadal hormone with multiple functions. Endocrine Reviews 14 152-164.

Mantero F, Terzolo M, Arnaldi G, Osella G, Masini AM, Ali A, Giovagnetti M, Opocher G \& Angeli A 2000 A survey on adrenal incidentaloma in Italy. Study group on adrenal tumors of the Italian society of endocrinology. Journal of Clinical Endocrinology and Metabolism 85 637-644.

Matzuk MM, Finegold MJ, Mather JP, Krummen L, Lu H \& Bradley A 1994 Development of cancer cachexia-like syndrome and adrenal tumors in inhibin-deficient mice. PNAS 91 8817-8821.

Mikola M, Kero J, Nilson JH, Keri RA, Poutanen M \& Huhtaniemi I 2003 High levels of luteinizing hormone analog stimulate gonadal and adrenal tumorigenesis in mice transgenic for the mouse inhibin-alpha-subunit promoter/Simian virus 40 T-antigen fusion gene. Oncogene 22 3269-3278.

Mishina Y, Rey R, Finegold MJ, Matzuk MM, Josso N, Cate RL \& Behringer RR 1996 Genetic analysis of the Mullerian-inhibiting substance signal transduction pathway in mammalian sexual differentiation. Genes and Development 10 2577-2587.
Nachtigal MW, Hirokawa Y, Enyeart-Van Houten DL, Flanagan JN, Hammer GD \& Ingraham HA 1998 Wilms' tumor 1 and Dax-1 modulate the orphan nuclear receptor SF-1 in sex-specific gene expression. Cell 93 445-454.

Rey R, Sabourin JC, Venara M, Long WQ, Jaubert F, Zeller WP, Duvillard P, Chemes H \& Bidart JM 2000 Anti-Mullerian hormone is a specific marker of sertoli- and granulosa-cell origin in gonadal tumors. Human Pathology 31 1202-1208.

Rilianawati, Paukku T, Kero J, Zhang FP, Rahman N, Kananen K \& Huhtaniemi I 1998 Direct luteinizing hormone action triggers adrenocortical tumorigenesis in castrated mice transgenic for the murine inhibin alpha-subunit promoter/simian virus $40 \mathrm{~T}$-antigen fusion gene. Molecular Endocrinology 12 801-809.

Robert NM, Tremblay JJ \& Viger RS 2002 Friend of GATA (FOG)-1 and FOG-2 differentially repress the GATA-dependent activity of multiple gonadal promoters. Endocrinology 143 3963-3973.

Schepers GE, Bullejos M, Hosking BM \& Koopman P 2000 Cloning and characterisation of the Sry-related transcription factor gene Sox8. Nucleic Acids Research 28 1473-1480.

Smith C \& Mackay S 1991 Morphological development and fate of the mouse mesonephros. Journal of Anatomy 174 171-184.

Spencer SJ, Rabinovici J, Mesiano S, Goldsmith PC \& Jaffe RB 1992 Activin and inhibin in the human adrenal gland. Regulation and differential effects in fetal and adult cells. Journal of Clinical Investigation 90 142-149.

Spencer SJ, Mesiano S, Lee JY \& Jaffe RB 1999 Proliferation and apoptosis in the human adrenal cortex during the fetal and perinatal periods: implications for growth and remodeling. Journal of Clinical Endocrinology and Metabolism 84 1110-1115.

Stikkelbroeck NM, Otten BJ, Pasic A, Jager GJ, Sweep CG, Noordam K \& Hermus AR 2001 High prevalence of testicular adrenal rest tumors, impaired spermatogenesis, and Leydig cell failure in adolescent and adult males with congenital adrenal hyperplasia. Journal of Clinical Endocrinology and Metabolism 86 5721-5728.

Viger RS, Mertineit C, Trasler JM \& Nemer M 1998 Transcription factor GATA-4 is expressed in a sexually dimorphic pattern during mouse gonadal development and is a potent activator of the Mullerian inhibiting substance promoter. Development 125 2665-2675.

Wilhelm D \& Englert C 2002 The Wilms tumor suppressor WT1 regulates early gonad development by activation of Sf1. Genes and Development 16 1839-1851.

Woolley GW \& Little CC 1945 The incidence of adrenal cortical carcinoma in gonadectomized female mice of the extreme dilution strain. I Observation on the adrenal cortex. Cancer Research 5 193-202.

Woolley GW \& Little CC 1946a Transplantation of an adrenal cortical carcinoma. Cancer Research 6 712-717.

Wolley GW \& Little CC $1946 b$ Prevention of adrenal cortical carcinoma by diethylstilbestrol. PNAS 32 239-240.

Wudy SA, Hartmann M \& Homoki J 2002 Determination of 11-deoxycortisol (Reichstein's compound S) in human plasma by clinical isotope dilution mass spectrometry using benchtop gas chromatography-mass selective detection. Steroids 67 851-857.

Zajicek G, Ariel I \& Arber N 1986 The streaming adrenal cortex: direct evidence of centripetal migration of adrenocytes by estimation of cell turnover rate. Journal of Endocrinology 111 477-482.
Received in final form 6 March 2006
Accepted 20 March 2006
Made available online as an Accepted Preprint 21 April 2006 